\title{
Forecasting tillage and soil warming effects on earthworm populations
}

Article

Accepted Version

Johnston, A. S. A., Sibly, R. M. and Thorbek, P. (2018)

Forecasting tillage and soil warming effects on earthworm populations. Journal of Applied Ecology, 55 (3). pp. 14981509. ISSN 0021-8901 doi: https://doi.org/10.1111/13652664.13096 Available at https://centaur.reading.ac.uk/75062/

It is advisable to refer to the publisher's version if you intend to cite from the work. See Guidance on citing.

To link to this article DOI: http://dx.doi.org/10.1111/1365-2664.13096

Publisher: Wiley

All outputs in CentAUR are protected by Intellectual Property Rights law, including copyright law. Copyright and IPR is retained by the creators or other copyright holders. Terms and conditions for use of this material are defined in the End User Agreement.

\section{www.reading.ac.uk/centaur}

\section{CentAUR}

Central Archive at the University of Reading

Reading's research outputs online 
DR ALICE SOPHIE ALEXANDRA JOHNSTON (Orcid ID : 0000-0001-8781-4039)

Article type : Research Article

Handling Editor: Lei Cheng

\section{FORECASTING TILLAGE AND SOIL WARMING EFFECTS ON EARTHWORM}

POPULATIONS

Johnston, A.S.A. ${ }^{a \star}$, Sibly, R.M. ${ }^{a}$, Thorbek, P. ${ }^{b}$

${ }^{a}$ A.S.A. Johnston, School of Biological Sciences, University of Reading, UK, alice.johnston@reading.ac.uk

${ }^{a}$ R.M. Sibly, School of Biological Sciences, University of Reading, UK, r.m.sibly@reading.ac.uk

${ }^{\mathrm{b}}$ P. Thorbek, Environmental Safety, Syngenta Ltd., Bracknell, UK, pernille.thorbek@syngenta.com

* Corresponding Author:

alice.johnston@reading.ac.uk

School of Biological Sciences, University of Reading, Reading, RG6 6AH

Tel +44(0)118378 6439

Running title: Tillage and soil warming effects on earthworm populations.

\section{ABSTRACT}

1. Healthy soils are crucial for sustainable food production, but tillage limits the biological regulation of essential ecosystem services. Better understanding of the

This article has been accepted for publication and undergone full peer review but has not been through the copyediting, typesetting, pagination and proofreading process, which may lead to differences between this version and the Version of Record. Please cite this article as doi: 10.1111/1365-2664.13096

This article is protected by copyright. All rights reserved. 
mechanisms driving management effects on soil ecosystem engineers is needed to support sustainable management under environmental change.

2. This paper presents the EEEworm (Energy - Environment - Earthworm) model, a mechanistic individual-based model (IBM) of Lumbricus terrestris populations. $L$. terrestris is a dominant earthworm species in undisturbed habitats and is closely associated with numerous ecosystem services such as water flow regulation, soil structure and crop production. In reduced tillage agriculture a decline in mechanical disturbance allows for $L$. terrestris proliferation, whilst the activities of $L$. terrestris can replace many of the soil functions provided by tillage.

3. Extensive EEEworm validation with eight published studies (average $R^{2}=0.84$ ) demonstrates a mechanistic approach which can extrapolate between diverse soil, management and weather conditions. EEEworm simulation experiments elucidate that a combination of direct and indirect tillage effects lead to population declines in tilled fields, with litter removal from the soil surface being the main driver.

4. We investigate the effects of different tillage intensities under historical and projected soil warming conditions, and find that future warmer and drier soils in our simulation exacerbate the effects of deep ploughing on L. terrestris population declines. These effects result from warmer and drier soil conditions increasing individual metabolic rates and tillage reducing food availability to meet energy demands.

5. Synthesis and applications. Pre-emptive strategies to mitigate climate change impacts on soil health in agroecosystems should focus on decreasing tillage intensity and retention of crop residues following tillage. EEEworm has the potential to benefit land managers, policy makers, risk assessors and regulators by providing a tool to forecast how soil systems respond to combinations of land management and environmental change. To allow better cost-benefit analysis of contrasting land management systems a future aim of mechanistic models like EEEworm is to incorporate the links between earthworm populations, soil functions and ecosystem services.

This article is protected by copyright. All rights reserved. 
Keywords: agriculture; earthworm; ecosystem engineer; environmental change; land management; Lumbricus terrestris; soil warming; tillage.

\section{INTRODUCTION}

Soils benefit the human population by facilitating essential ecosystem services such as food production, climate regulation and nutrient cycling (Power 2010). Crucial for a growing human population are the foundations that soils provide for agriculture. However, tillage practices (e.g. moldboard ploughing) have led to extensive soil degradation, placing increasing pressure on ecosystem service delivery (Palm et al. 2014). To sustain ecosystem services in agriculture a shift in management is needed toward the biological regulation of ecosystem services by the soil biota (Bender, Wagg \& van der Heijden 2016). Within soils, ecosystem engineers are important in facilitating the soil functions that underpin ecosystem services (Barrios 2007).

Earthworms have been identified as the most important ecosystem engineers in soils and are widely considered important bio-indicators of soil health (van Capelle, Schrader \& Brunotte 2012). By burrowing through the soil, earthworms produce large pores that are important for water flow and retention, aeration, and root development. They help mix organic materials into the soil and aid in aggregate formation, whilst relationships with microorganisms play an essential role in nutrient cycling and organic matter decomposition (Kladivko 2001). Different earthworm species play different roles in soil functioning, which are reflected by their functional groups: epigeic, anecic or endogeic. Epigeics are litter transformers, mineralizing and digesting plant remains at the soil surface, anecics inhabit semi-permanent vertical burrows originating at the soil surface whilst endogeics form temporary horizontal burrows in the mineral soil (Bouché 1977).

This article is protected by copyright. All rights reserved. 
Anecic earthworms have been shown to increase crop yields and aboveground biomass (van Groenigen et al. 2014), water infiltration rates which reduce surface run-off associated with accelerating soil erosion and flooding (Andriuzzi et al. 2015), $\mathrm{N}$ mineralization from crop residues which promotes plant production (van Groenigen et al. 2014) and soil organic carbon (SOC) stocks which is closely associated with nutrient availability and plant quality (Shuster, Subler \& McCoy 2001). However, anecic earthworm populations are significantly reduced in agricultural fields due to tillage (van Capelle, Schrader \& Brunotte 2012). Climatic factors also moderate earthworm populations and can directly influence their response to tillage practices (Briones \& Schmidt 2017). Understanding the mechanisms driving both tillage and climate effects on anecic earthworms is thus important in better informing sustainable agriculture in uncertain future conditions.

Tools are needed to better predict how combinations of land management and climate change scenarios affect the provision of ecosystem services from soils. Population models show promise for gaining insights into the feedbacks between populations, management and climate systems, but most are either not realistic or not flexible enough for wide scale application. Statistical models or models that project current situations are also little suited to extrapolation outside the range they are parameterised, and so may be unreliable for prediction under novel future conditions including environmental change (Urban et al. 2016). Mechanistic models which capture key biological, physiological and ecological mechanisms underpinning system functioning should have better predictive power (Evans, Norris \& Benton 2012).

In this paper we present the EEEworm (Energy - Environment - Earthworm) model, a mechanistic individual-based model (IBM) of the anecic earthworm Lumbricus terrestris in the soil system. The model is developed from a previously published mechanistic model, which has demonstrated excellent predictive power for endogeic earthworms (Johnston et al. 2015). During model simulations, individual physiology and behaviour respond to trade-offs 
in prevailing environmental conditions, and population dynamics emerge. Here, we validate EEEworm's ability to capture numerous patterns in L. terrestris life cycles and population dynamics in various environmental and management scenarios. We use model experiments to elucidate how tillage achieves its effects on L. terrestris populations, and apply EEEworm to forecast long-term population responses to different tillage intensities under soil warming conditions.

\section{MATERIALS AND METHODS}

EEEworm builds on the same principles as previously published models of the epigeic earthworm Eisenia fetida and the endogeic earthworm Aporrectodea caliginosa, namely the combination of energy budgets and movement in response to trade-offs in environmental conditions (Johnston et al. 2014a; Johnston et al. 2014b; Johnston et al. 2015). Previous models proceeded in daily time-steps and represented 2D cross-sections of the soil surface for epigeic or the soil profile for endogeic earthworms, set up with $10 \times 10 \mathrm{~cm}$ patches and species-specific energy budget parameters and behavioural rules. Here, EEEworm is adapted for the behavioural (e.g. burrowing) and physiological (e.g. life cycle) traits of the anecic earthworm Lumbricus terrestris, an important soil ecosystem engineer in no-till agriculture and natural ecosystems.

\section{MODEL OVERVIEW}

EEEworm represents individual earthworms with their own energy budgets and behavioural decisions, interacting with each other and their environment in a spatially explicit IBM. The model environment represents a vertical cross-section of a soil profile, comprising $1 \times 1 \mathrm{~cm}$ soil patches characterised by soil temperature, water content, texture, bulk density, soil organic matter (SOM) and plant litter quantity and quality inputs (Fig. 1). EEEworm proceeds in hourly time-steps here with a 12:12 hour day:night cycle. Daily and seasonal fluctuations in soil conditions (e.g. soil temperature, SOM, plant litter), are modelled according to 
observed seasonal and vertical relationships (for further details see Johnston et al. (2014b) and Johnston et al. (2015) and Appendix S1 of the Supporting Information).

(Figure 1 here)

Individual energy budgets describe how individuals acquire energy from food and expend energy on life cycle processes in priority order: maintenance, reproduction, growth and energy storage (Fig. 1). Population dynamics then emerge from the collective activities of individuals and their interactions in heterogeneous soil environments. EEEworm model parameters are presented in Table 1, together with their units and sources. Additional model details are provided in Appendix S1 of the Supporting Information. The EEEworm model NetLogo program code developed by Alice Johnston is Copyright (C) 2017 University of Reading and licensed under the GNU General Public Licence version 3 (Appendix S2 of the Supporting Information).

(Table 1 here)

Individual behaviour is modelled according to individual life stage, size, energy status, and environmental and population density conditions. Inevitably, some of the complex behaviours exhibited by L. terrestris are simplified in the EEEworm model. A conceptual model of the behavioural decisions made by individuals in hourly time-steps are outlined in Fig. 2. Modelled behaviour is described in the following sections and further details are given in Appendix S1 of the Supporting Information.

(Figure 2 here)

Form burrow. If an individual does not already inhabit a burrow, it will prioritise energy expenditure to burrow formation above growth and reproduction. Potential new burrow sites

This article is protected by copyright. All rights reserved. 
must leave a minimum distance of $20 \mathrm{~cm}$ between neighbouring burrows (Nuutinen \& Butt 2005). If the population is space-limited, co-habitation of a single burrow can occur between a maximum of two adults, whilst cohabitation of a burrow between a parent and its juvenile offspring can occur at any time (Lowe \& Butt 2002; Grigoropoulou, Butt \& Lowe 2008). Burrows are modelled as vertical structures, running from the soil surface to deeper soil depths as in Fig. 1. The vertical elongation of a burrow depends on the occurrence of favourable soil patches at greater soil depths.

Move in burrow. During daylight periods individuals stay within their burrows to avoid high predation risk. While in their burrow, individuals optimise their position according to nonlinear trade-offs between food quality, soil temperature and water potential conditions. In EEEworm the favourability of different soil and burrow patches are represented by an index of patch quality (Fig. S7 of the Supporting Information). Individuals sense patch quality within their burrow and preferentially move towards vertical patches with a higher index of patch quality. If a neighbouring soil patch is more favourable than an individual's existing burrow patch, it will extend its burrow to include this patch if the associated energy requirements of burrowing can be met. Individuals may ingest soil if energy requirements cannot be met during daylight hours, or if there is insufficient availability of litter (e.g. (Marhan \& Scheu 2005).

Mate at surface. Adult $L$. terrestris are hermaphroditic earthworms which require copulation with other adults every 3 months to transfer sperm and produce cocoons (Butt \& Nuutinen 1998). In EEEworm, when an individual requires a mate it will sense the presence of another adult within a $20 \mathrm{~cm}$ radius of itself at the soil surface during dark hours. If another adult is available within this area, the individual will move towards the other adult until they mate. Adults can then produce cocoons for 3 months after copulation, before needing to mate again.

Forage at surface. Individuals forage on plant litter at the soil surface, typically within a 50 $\mathrm{cm}$ radius of the burrow mouth (Nuutinen \& Butt 2005). If food is limited, individuals can

This article is protected by copyright. All rights reserved. 
forage to greater distances from their burrows and return to a closer unoccupied burrow if available at day light.

\section{MODEL VALIDATION}

Model validation is crucial in testing whether a model can predict individual and populationlevel dynamics in a range of environmental and management conditions. During model validation EEEworm simulates the conditions of published individual- and population-level experiments, and model outputs are compared to the independent published data. Full experimental details for model simulations are presented in Appendix S1 of the Supporting Information, and a summary of each is provided in the following sections.

Individual-level experiments. We simulated five different experiments which observed the effects of food quantity and quality, intraspecific competition, soil temperature and moisture on L. terrestris growth and reproduction, summarised in Table 2.

Vertical distribution of L. terrestris populations in pasture. Gerard (1967) reported the proportion of an L. terrestris population found at different soil depths throughout the year at Rothamsted, UK. Seasonal soil temperature and soil water potential are summarised in Fig. 1.

Population responses to tillage practices. Pelosi et al. (2008) recorded total, adult and juvenile population densities under fields formerly surface tilled (to $10 \mathrm{~cm}$ ) or deep ploughed (to $30 \mathrm{~cm}$ ) during two study years in France. Plots were cultivated with spring barley in 2006 and winter barley in 2007. The different tillage practices were modelled according to the study: surface tillage to a soil depth of $10 \mathrm{~cm}$ and deep ploughing to a soil depth of $30 \mathrm{~cm}$, both annually on $1^{\text {st }}$ October before the start of the field trial. EEEworm populations were sampled on the sample dates and to a soil depth of $30 \mathrm{~cm}$ as in the field sampling. Edwards and Lofty (1982) recorded total L. terrestris population density with annually direct drilled (5 $\mathrm{cm})$, chisel ploughed $(12.5 \mathrm{~cm})$ or deep ploughed $(20 \mathrm{~cm})$ practices over a five year period in England. Soil temperature and water content measurements were extracted from the electronic Rothamsted Archive (e-RA) (Fig. 3a: light blue and green symbols represent 
experimental period). Direct drilling, chisel ploughing and deep ploughing practices, to 5 , 12.5 and $20 \mathrm{~cm}$ soil depths respectively, were simulated once a year on $1^{\text {st }}$ October. EEEworm populations were sampled on $15^{\text {th }}$ September or May to a soil depth of $20 \mathrm{~cm}$ as in the field sampling.

(Table 2 here)

\section{Modelling tillage effects}

Direct mortality. Here, we take a direct earthworm mortality rate of $50 \%$ during tillage, as was used for endogeic earthworms (Johnston et al. 2015). There is little evidence to support a higher or lower direct mortality rate for anecic earthworms. For instance, Crittenden et al. (2014) found earthworm populations to decline by $70 \%$ five days after moldboard ploughing in conventional arable fields. Longer-term data suggests higher mortality rates but this is presumably a combination of direct and indirect effects on soil conditions (e.g. (Wyss \& Glasstetter 1992). In EEEworm, the $50 \%$ mortality rate is applied to the population present in the tilled soil layers, which depends on tillage practice.

Litter removal. The amount of plant litter at the soil surface is reduced following tillage events, and retained litter is redistributed within the tilled soil layers. The amount of plant residue that is retained varies between the surface tilled/direct drilled and chisel/deep ploughed scenarios. Yang and Wander (1999) reported litter retention of $78 \%$ and $0.08 \%$ in disk tilled and moldboard ploughed fields respectively, compared to no-till control plots. These values were used to model reductions in the quantity of litter available following tillage events, presented in Fig. S9 of the Supporting Information.

Burrow destruction. Burrow structures are destroyed by converting $100 \%$ of the burrow patches in the tilled/ploughed soil layers to soil patches.

This article is protected by copyright. All rights reserved. 


\section{Model evaluation}

Data used to build and parameterise IBMs should be independent of the data used for model validation. As a simple measure of EEEworm's 'goodness of fit' to independent data we use coefficient of determination $\left(R^{2}\right)$ values, calculated as: 1 - ((residual sum of squares)/(total sum of squares)), with values closer to 1 representing better agreement between observed and predicted values. Note that if the model does not follow the trend of the data (e.g. the residual sum of squares from the model is higher than the total sum of squares from the data) the value of $R^{2}$ can be negative. As in Johnston et al. (2015), our model parameter values are not estimated from the data and so conventional statistical methods of assessing $R^{2}$ values (using $p$ values) are not applicable. Values of $R^{2}>0.5$ are taken to indicate good prediction of the independent data.

\section{MODEL APPLICATION}

EEEworm was applied to simulate the long-term (116 year) effects of tillage practices on $L$. terrestris populations under historical and projected weather conditions for Rothamsted, UK. The tillage practices simulated were direct drilling and chisel and deep ploughing to $5,12.5$ and $20 \mathrm{~cm}$ respectively, as described in Edwards and Lofty (1982). Sixty six years of historical weather data (1950-2016: Fig. 3a) was extracted from the electronic Rothamsted archive (e-RA), with the initial five year period (1950-1955) used to stabilise the model population. Future 'baseline' weather projections for the next 50 years (2017-2067) were constructed as an extrapolation of observed increases and variations in soil temperature and water potentials over the previous 50 years (1966-2016) (Fig. 3b).

(Figure 3 here)

This article is protected by copyright. All rights reserved. 


\section{RESULTS}

\section{MODEL VALIDATION}

Individual growth and reproduction. The EEEworm model was able to capture the overall patterns in individual growth and reproduction recorded in the published experiments simulated (Fig. 4), with an average $R^{2}$ value of 0.87 . Four studies measured changes in individual biomass (Figs $4 a-d$ ) and two studies cocoon production (Figs $4 e$ \& f) over time, maintained at different densities, food quantities, diets, and soil moistures and temperatures. Increases in life cycle processes when individuals experience less competition for food resources (Fig. 4a) or were provided higher energy content foods (Figs 4a, d \& f) are predicted well by the energy budget model as more energy is available for expenditure to growth and reproduction. General patterns of increased biomass at higher soil moistures and lower temperatures are also captured by EEEworm, and mortality at higher temperatures in starvation conditions is also predicted well (Figs $4 b$ \& c). All model predictions except one (Fig. 4d: birch leaf diet) can be classified as 'good' according to the goodness of fit test $\left(R^{2}>\right.$ 0.5). While EEEworm underestimated the difference between manure and birch leaves in Fig. $4 d$, it did capture the overall temporal pattern of the two diets.

(Figure 4 here)

Vertical distribution of L. terrestris populations in pasture. EEEworm predictions of the vertical distribution of $L$. terrestris populations agree well with recorded data from Gerard (1967) (Fig. 5, $R^{2}=0.68$ ), capturing important drivers of individual movement to deeper soil depths, such as migration to deeper soil layers during dry soil conditions in September.

(Figure 5 here)

This article is protected by copyright. All rights reserved. 
Population responses to tillage and ploughing practices. EEEworm predictions of $L$. terrestris population densities in response to tillage and ploughing practices are reported in Fig. 6 for the field trial presented by Pelosi et al. (2008) and Fig. 7 for the field trial by Edwards and Lofty (1982). Pelosi et al. (2008)'s field experiment recorded earthworm populations after the cessation of annual surface tillage and deep ploughing practices one year before the different field trials (i.e. 2006 and 2007 represent different plots, with tillage practices stopped in 2005 or 2006 respectively). Initial population densities, population structure and seasonal fluctuations in population density according to prevailing environmental conditions in the top $30 \mathrm{~cm}$ of the soil profile sampled are captured by EEEworm $\left(R^{2}=0.82\right)$.

(Figure 6 here)

Edwards and Lofty (1982)'s study demonstrates an increasingly detrimental effect of tillage intensity on L. terrestris populations in the top $20 \mathrm{~cm}$ of the soil profile sampled, which EEEworm captures well $\left(R^{2}=0.90\right)$ (Fig. 7). Average tillage effects (ploughed divided by direct drilled population density) are 0.44 and 0.56 for chisel ploughing in the data and EEEworm, respectively, and 0.16 and 0.28 for deep ploughing in the data and EEEworm, respectively. Differences between L. terrestris population densities sampled by Edwards and Lofty (1982) and Pelosi et al. (2008) are also captured by EEEworm due to variations in soil and environmental conditions, tillage frequency and the soil depth sampled.

(Figure 7 here)

Tillage effects. Comparisons between EEEworm predictions of tillage effects on L. terrestris populations (ploughed divided by direct drilled population density) and data from Edwards and Lofty (1982) when all tillage effects are included (as in Fig. 7) or when direct mortality, litter removal and burrow destruction effects are removed, are presented in Fig. 8. There is a 
reduced goodness of fit between the model and data when any tillage effect is removed. EEEworm predictions are particularly sensitive to litter removal $\left(R^{2}=-0.73\right)$, followed by burrow destruction $\left(R^{2}=0.28\right)$ and direct mortality $\left(R^{2}=0.61\right)$, compared to model predictions when all tillage effects are included $\left(R^{2}=0.86\right)$.

(Figure 8 here)

\section{MODEL APPLICATION}

EEEworm forecasts of ploughing effects on L. terrestris populations in arable fields over 111 years are presented in Fig. 9. Results follow the common trend of increasing ploughing effect (decreasing population density) with increasing tillage intensity reported in Edwards and Lofty (1982). In the chisel ploughed scenario, L. terrestris populations decline to below $50 \%$ of the direct drilled population density post-2015, whilst the deep ploughed population declines to below $20 \%$ of the direct drilled population post-2013. In contrast, the direct drilled population (which experiences only small tillage-induced effects on direct earthworm mortality) increases over time, with (albeit very weak) positive correlation between population density and soil temperature and water potential. Populations in the chisel ploughed scenarios tend to stabilise at a lower density post-2015 and only show a moderate negative relationship with soil temperature and water potential, whilst deep-ploughed populations continue to decline and show a stronger negative relationship with soil temperature and water potential (Figs 9b \& c).

(Figure 9 here)

\section{DISCUSSION}

The mechanistic EEEworm model indicates that tillage effects on important soil ecosystem engineers (Lumbricus terrestris) are driven by the removal of plant litter from the soil surface, while interactions between litter removal, mortality and burrow destruction are key in 
predicting population responses to different tillage intensities (Fig. 8a). Under soil warming, higher soil temperatures and reduced soil water potentials in our weather scenario place additional energetic demands on individual earthworms (Figs $4 b$ \& c), and when demands cannot be met with sufficient food resources population declines are exacerbated (Fig. 9). In EEEworm, greater population declines in deep ploughed scenarios are due to greater plant litter depletion, which intensifies temperature and soil water stress on populations (Figs 9b \& c). Yet, simulations also showed that deep and chisel ploughed populations avoid total collapse under continued disturbance through L. terrestris adaptive behaviour: individuals burrow to deeper soil depths to avoid increasingly dry conditions in the tilled soil layers. In contrast to the ploughed scenarios, L. terrestris populations responded positively to soil warming under direct drilling, where sufficient food was available to meet the energy costs associated with higher metabolic rates. The importance of $L$. terrestris as an ecosystem engineer suggests that their higher population abundances in direct drilled fields provide a suite of soil functions essential for improving plant growth (Spurgeon et al. 2013; van Groenigen et al. 2014).

In line with our predictions, Simonsen et al. (2010) reported decreasing adult $L$. terrestris population densities from $28 / \mathrm{m}^{2}$ in no-till to $3 / \mathrm{m}^{2}$ in chisel ploughed fields in Wisconsin, whilst Stroud et al. (2016) observed densities $<1 / \mathrm{m}^{2}$ in long-term conventionally managed plots at Rothamsted.

Here, we predict average $L$. terrestris population densities of 29,13 and $4 / \mathrm{m}^{2}$ in direct drilled, chisel and deep ploughed scenarios after 51 simulation years under historical weather conditions at Rothamsted. Our finding that tillage effects are strongly influenced by litter layer removal is further supported by observed positive correlations between organic amendment quantity and L. terrestris abundance in arable fields (Sizmur et al. 2017). Vice versa, the positive effects of no-till systems on anecic earthworms are due to improved food availability alongside a lack of physical disturbance. In a global meta-analysis, Briones and Schmidt (2017) found that no-till systems (compared to conventional controls) had a

This article is protected by copyright. All rights reserved. 
particularly positive effect on $L$. terrestris abundance which increased by $178 \%$ compared to an overall earthworm abundance increase of $137 \%$. These results indicate the importance of litter retention for optimal management of ecosystem functions facilitated by this important ecosystem engineer.

Long-term responses of earthworms to soil warming have not been well studied. However, a study in temperate grassland showed soil warming to significantly increase anecic earthworm numbers, while endogeic and epigeic populations declined (Briones et al. 2009). This response was likely due to the ability of anecic earthworms to burrow to much deeper soil layers than other functional groups of earthworm, aiding better adaptation to adverse soil surface conditions. Whether earthworms acclimatise to soil warming is unknown, and adaptive strategies towards temperature shifts likely depend on species-specific behaviours (Chuang, Lee \& Chen 2004). The direction and magnitude of warming effects on earthworm abundance will also be strongly influenced by soil water conditions (Eisenhauer et al. 2014) and plant litter availability and quality (Daniel 1991). Yet, while we know that earthworms exhibit preferences for specific environmental conditions, and here EEEworm predictions of individual weight gain and loss at different soil moistures and temperatures agree well with published data (Figs $4 b \& c$ ), more knowledge is needed on how extreme events affect individual life cycles. For instance, very little is known about the effects of flood and drought conditions on earthworm physiology and behaviour and the resultant effects that this may have on soil health. In the same way, plant production and quality will likely be altered under environmental change, shifting the relationships between earthworms, soil functions and plant productivity (Wardle et al. 2004). Understanding how soil organisms are affected by various scenarios of environmental change, ideally through coupled empirical and modelling studies, would allow better prediction of soil populations in both managed and unmanaged ecosystems.

This article is protected by copyright. All rights reserved. 
Whether anecic earthworms can replace the soil functions provided by tillage will depend on a number of site-specific factors, and predictive tools need further development to identify best practices for sustainable soil management at the field scale. A clear aim for modelling approaches like EEEworm is to link individual earthworm activities and population dynamics to ecosystem functions. This would require: 1) linking individual activities (movement, burrowing, casting, foraging) to changes in soil structure and properties (e.g. aggregation, bulk density, water infiltration rates); 2) linking biogenetic structures (e.g. burrows, casts) to soil microbial populations; 3) representation of the nutritional ecology of earthworms within the soil system and feedback to nutrient and carbon cycles; 4) interactions with other soil organisms and functional groups within soil food webs; and 5) interactions with plant components (e.g. roots) and feedbacks between plant life cycles. Empirical studies quantifying the specific relationships between soil biota activities and soil functions are needed to support these developments.

Mechanistic models are needed to find pathways to sustainable land management, by identifying how land management and climate change affect ecosystem functioning. $L$. terrestris is a keystone species closely associated with essential soil functions and ecosystem services such as primary productivity, soil fertility and flood prevention. Experimental evidence (e.g. Stroud et al. 2016) and our simulations suggest $L$. terrestris populations are decimated by deep ploughing mainly due to removal of the litter layer following tillage. In the context of soil warming through climate change, removal of the litter layer will exacerbate L. terrestris population declines in ploughed fields if soil conditions also become drier as in our simulation. Our results suggest that pre-emptive strategies to mitigate climate change impacts on soil health in agroecosystems should focus on decreasing tillage intensity and retaining crop residues and organic amendments at the soil surface. As $L$. terrestris vulnerability varies seasonally, recommendations for conserving L. terrestris populations will depend on site-specific combinations of environmental conditions and 
management practices. Tools like EEEworm are needed to better inform sustainable land management strategies.

\section{Authors' contributions}

AJ, RS and PT conceived the ideas and designed methodology; AJ and PT developed the conceptual model; AJ collected literature data, wrote the model code, and conducted and analysed model simulations; AJ and RS led the writing of the manuscript. All authors contributed critically to the drafts and gave final approval for publication.

\section{Acknowledgements}

We thank Dr Celine Pelosi for sharing of field data, and the Lawes Agricultural Trust and

Rothamsted Research for data from the e-RA database. The Rothamsted Long-term

Experiments National Capability (LTE-NCG) is supported by the UK Biotechnology and

Biological Sciences Research Council and the Lawes Agricultural Trust. This research has been financially supported by a NERC Soil Security Programme fellowship (NE/N019504/1).

\section{Data accessibility}

- NetLogo model implementation: Zenodo DOI: 10.5281/zenodo.1123250 (Johnston 2018a)

- EEEworm model outputs and weather input files: University of Reading Research Data

Archive DOI: 10.17864/1947.133 (Johnston 2018b).

\section{References}

Andriuzzi, W.S., Pulleman, M.M., Schmidt, O., Faber, J.H. \& Brussaard, L. (2015) Anecic earthworms (Lumbricus terrestris) alleviate negative effects of extreme rainfall events on soil and plants in field mesocosms. Plant and Soil, 397, 103-113.

Barrios, E. (2007) Soil biota, ecosystem services and land productivity. Ecological Economics, 64, 269-285.

Bender, S.F., Wagg, C. \& van der Heijden, M.G.A. (2016) An Underground Revolution: Biodiversity and Soil Ecological Engineering for Agricultural Sustainability. Trends in Ecology \& Evolution, 31, 440-452.

Berry, E.C. \& Jordan, D. (2001) Temperature and soil moisture content effects on the growth of Lumbricus terrestris (Oligochaeta: Lumbricidae) under laboratory conditions. Soil Biology and Biochemistry, 33, 133-136.

Bouché, M.B. (1977) Strategies lombriciennes. Ecological Bulletins, 122-132.

This article is protected by copyright. All rights reserved. 
Briones, M.J.I., Ostle, N.J., McNamara, N.P. \& Poskitt, J. (2009) Functional shifts of grassland soil communities in response to soil warming. Soil Biology and Biochemistry, 41, 315-322.

Briones, M.J.I. \& Schmidt, O. (2017) Conventional tillage decreases the abundance and biomass of earthworms and alters their community structure in a global metaanalysis. Global Change Biology, n/a-n/a.

Butt, K.R. (1993) Utilisation of solid paper-mill sludge and spent brewery yeast as a feed for soil-dwelling earthworms. Bioresource Technology, 44, 105-107.

Butt, K.R. (2011) Food quality affects production of Lumbricus terrestris (L.) under controlled environmental conditions. Soil Biology and Biochemistry, 43, 2169-2175.

Butt, K.R., Frederickson, J. \& Morris, R.M. (1992) The intensive production of lumbricus terrestris L. for soil amelioration. Soil Biology and Biochemistry, 24, 1321-1325.

Butt, K.R. \& Nuutinen, V. (1998) Reproduction of the earthworm Lumbricus terrestris Linné after the first mating. Canadian Journal of Zoology, 76, 104-109.

Chuang, S.C., Lee, H. \& Chen, J.H. (2004) Diurnal rhythm and effect of temperature on oxygen consumption in earthworms, Amynthas gracilis and Pontoscolex corethrurus. Journal of Experimental Zoology Part A: Comparative Experimental Biology, 301A, 737-744.

Crittenden, S.J., Eswaramurthy, T., de Goede, R.G.M., Brussaard, L. \& Pulleman, M.M. (2014) Effect of tillage on earthworms over short- and medium-term in conventional and organic farming. Applied Soil Ecology, 83, 140-148.

Curry, J.P. \& Bolger, T. (1984) Growth, reproduction and litter and soil consumption by Lumbricus terrestris L. in reclaimed peat. Soil Biology and Biochemistry, 16, 253-257.

Daniel, O. (1990) Life cycle and population dynamics of the earthworm Lumbricus terrestris L.

Daniel, O. (1991) Leaf-litter consumption and assimilation by juveniles of Lumbricus terrestris L.(Oligochaeta, Lumbricidae) under different environmental conditions. Biology and Fertility of Soils, 12, 202-208.

Daniel, O., Kohli, L. \& Bieri, M. (1996) Weight gain and weight loss of the earthworm Lumbricus terrestris L. at different temperatures and body weights. Soil Biology and Biochemistry, 28, 1235-1240.

Edwards, C.A. \& Lofty, J.R. (1982) The Effect of Direct Drilling and Minimal Cultivation on Earthworm Populations. Journal of Applied Ecology, 19, 723-734.

Ehnes, R.B., Rall, B.C. \& Brose, U. (2011) Phylogenetic grouping, curvature and metabolic scaling in terrestrial invertebrates. Ecology letters, 14, 993-1000.

Eisenhauer, N., Stefanski, A., Fisichelli, N.A., Rice, K., Rich, R. \& Reich, P.B. (2014) Warming shifts 'worming': effects of experimental warming on invasive earthworms in northern North America. Scientific Reports, 4, 6890.

Evans, M.R., Norris, K.J. \& Benton, T.G. (2012) Predictive ecology: systems approaches. Philosophical Transactions of the Royal Society B: Biological Sciences, 367, 163169.

Gerard, B.M. (1967) Factors Affecting Earthworms in Pastures. Journal of Animal Ecology, $36,235-252$.

Grigoropoulou, N., Butt, K.R. \& Lowe, C.N. (2008) Effects of adult Lumbricus terrestris on cocoons and hatchlings in Evans' boxes. Pedobiologia, 51, 343-349.

Johnston, A.S.A., Hodson, M.E., Thorbek, P., Alvarez, T. \& Sibly, R.M. (2014a) An energy budget agent-based model of earthworm populations and its application to study the effects of pesticides. Ecological Modelling, 280, 5-17.

Johnston, A.S.A., Holmstrup, M., Hodson, M.E., Thorbek, P., Alvarez, T. \& Sibly, R.M. (2014b) Earthworm distribution and abundance predicted by a process-based model. Applied Soil Ecology, 84, 112-123.

Johnston, A.S.A., Sibly, R.M., Hodson, M.E., Alvarez, T. \& Thorbek, P. (2015) Effects of agricultural management practices on earthworm populations and crop yield: validation and application of a mechanistic modelling approach. Journal of Applied Ecology, 52, 1334-1342.

This article is protected by copyright. All rights reserved. 
Johnston, A.S.A (2018a) Netlogo code for the EEEworm (Energy - Environment Earthworm) model of Lumbricus terrestris populations (Version 1.0.0). Zenodo http://doi.org/10.5281/zenodo.1123251

Johnston, A.S.A. (2018b) Input, validation and output data for the mechanistic earthworm (Lumbricus terrestris) population model, EEEworm. University of Reading. Dataset. http://dx.doi.org/10.17864/1947.133

Kladivko, E.J. (2001) Tillage systems and soil ecology. Soil and Tillage Research, 61, 61-76.

Lowe, C.N. \& Butt, K.R. (2002) Influence of organic matter on earthworm production and behaviour: a laboratory-based approach with applications for soil restoration. European Journal of Soil Biology, 38, 173-176.

Marhan, S. \& Scheu, S. (2005) Effects of sand and litter availability on organic matter decomposition in soil and in casts of Lumbricus terrestris L. Geoderma, 128, 155166.

Nuutinen, V. \& Butt, K.R. (2005) Homing ability widens the sphere of influence of the earthworm Lumbricus terrestris L. Soil Biology and Biochemistry, 37, 805-807.

Palm, C., Blanco-Canqui, H., DeClerck, F., Gatere, L. \& Grace, P. (2014) Conservation agriculture and ecosystem services: An overview. Agriculture, Ecosystems \& Environment, 187, 87-105.

Pelosi, C., Bertrand, M., Makowski, D. \& Roger-Estrade, J. (2008) WORMDYN: A model of Lumbricus terrestris population dynamics in agricultural fields. Ecological Modelling, 218, 219-234.

Peters, R.H. (1983) The ecological implications of body size. Cambridge University Press.

Power, A.G. (2010) Ecosystem services and agriculture: tradeoffs and synergies. Philosophical Transactions of the Royal Society B: Biological Sciences, 365, 29592971.

Quillin, K.J. (2000) Ontogenetic scaling of burrowing forces in the earthworm Lumbricus terrestris. J Exp Biol, 203, 2757-2770.

Shuster, W.D., Subler, S. \& McCoy, E.L. (2001) Deep-burrowing earthworm additions changed the distribution of soil organic carbon in a chisel-tilled soil. Soil Biology and Biochemistry, 33, 983-996.

Sibly, R.M. \& Calow, P. (1986) Physiological ecology of animals : an evolutionary approach. Blackwell Scientific, Oxford [England].

Simonsen, J., Posner, J., Rosemeyer, M. \& Baldock, J. (2010) Endogeic and anecic earthworm abundance in six Midwestern cropping systems. Applied Soil Ecology, 44, 147-155.

Sizmur, T., Martin, E., Wagner, K., Parmentier, E., Watts, C. \& Whitmore, A.P. (2017) Milled cereal straw accelerates earthworm (Lumbricus terrestris) growth more than selected organic amendments. Applied Soil Ecology, 113, 166-177.

Spurgeon, D.J., Keith, A.M., Schmidt, O., Lammertsma, D.R. \& Faber, J.H. (2013) Land-use and land-management change: relationships with earthworm and fungi communities and soil structural properties. BMC Ecology, 13, 46.

Stroud, J.L., Irons, D.E., Watts, C.W., White, R.P., McGrath, S.P. \& Whitmore, A.P. (2016) Population collapse of Lumbricus terrestris in conventional arable cultivations and response to straw applications. Applied Soil Ecology, 108, 72-75.

Urban, M.C., Bocedi, G., Hendry, A.P., Mihoub, J.-B., Pe'er, G., Singer, A., Bridle, J.R., Crozier, L.G., De Meester, L., Godsoe, W., Gonzalez, A., Hellmann, J.J., Holt, R.D., Huth, A., Johst, K., Krug, C.B., Leadley, P.W., Palmer, S.C.F., Pantel, J.H., Schmitz, A., Zollner, P.A. \& Travis, J.M.J. (2016) Improving the forecast for biodiversity under climate change. Science, 353.

van Capelle, C., Schrader, S. \& Brunotte, J. (2012) Tillage-induced changes in the functional diversity of soil biota - a review witha focus on German data. Eur J Soil Biol, $\mathbf{5 0 .}$

van Groenigen, J.W., Lubbers, I.M., Vos, H.M.J., Brown, G.G., De Deyn, G.B. \& van Groenigen, K.J. (2014) Earthworms increase plant production: a meta-analysis. Scientific Reports, 4, 6365.

This article is protected by copyright. All rights reserved. 
Wardle, D.A., Bardgett, R.D., Klironomos, J.N., Setälä, H., van der Putten, W.H. \& Wall, D.H. (2004) Ecological Linkages Between Aboveground and Belowground Biota. Science, 304, 1629-1633.

Wyss, E. \& Glasstetter, M. (1992) Tillage treatments and earthworm distribution in a swiss experimental corn field. Soil Biology and Biochemistry, 24, 1635-1639.

Yang, X.-M. \& Wander, M.M. (1999) Tillage effects on soil organic carbon distribution and storage in a silt loam soil in Illinois. Soil and Tillage Research, 52, 1-9.

\section{Supporting Information}

Additional Supporting Information may be found in the online version of this article:

Appendix S1. Additional details of EEEworm model parameters, variables and simulations. 
Table 1. Default parameter values of the Lumbricus terrestris EEEworm model with sources.

\begin{tabular}{|c|c|c|c|c|c|}
\hline Symbol & Definition & Value & Unit & Reference & Notes \\
\hline$A_{e}$ & Assimilation efficiency & 0.55 & --- & Daniel (1991) & p. 207 \\
\hline$B_{0}$ & $\begin{array}{l}\text { Taxon-specific } \\
\text { normalization constant }\end{array}$ & 360 & --- & $\begin{array}{l}\text { Ehnes, Rall and } \\
\text { Brose (2011) }\end{array}$ & $\begin{array}{l}\text { Data given as } \\
\text { Supporting Information. }\end{array}$ \\
\hline$E$ & Activation energy & 0.32 & $\mathrm{eV}$ & & \\
\hline$E_{c}$ & Energy content of tissue & 7 & $\mathrm{~kJ} / \mathrm{g}$ & Peters (1983) & p. 235 \\
\hline$E_{s}$ & Energy cost of synthesis & 3.6 & $\mathrm{~kJ} / \mathrm{g}$ & $\begin{array}{l}\text { Sibly and Calow } \\
(1986)\end{array}$ & p. $54-55$ \\
\hline$E_{x}$ & Energy content of food & $0.56-21.2$ & $\mathrm{~kJ} / \mathrm{g}$ & \multicolumn{2}{|c|}{ Range depends on diet: see text. } \\
\hline$I G_{\max }$ & Maximum ingestion rate & 0.37 & $\mathrm{~g} /$ hour $/ \mathrm{g}^{2 / 3}$ & $\begin{array}{l}\text { Curry and Bolger } \\
(1984)\end{array}$ & Fig. 3, p. 255. \\
\hline$B_{c}$ & Energy cost of burrowing & 0.0103 & $\mathrm{~kJ} / \mathrm{cm} /$ hour & Quillin (2000) & Fig. $6 \mathrm{~b}$ and Table 1 \\
\hline$M_{b}$ & Mass at birth & 0.053 & $g$ & Butt (1993) & Fig. 1, p. 136 \\
\hline$M_{c}$ & Mass of cocoon & 0.061 & $g$ & Butt (1993) & Table 1, p. 137 \\
\hline$M_{p}$ & Mass at sexual maturity & 4.2 & $g$ & $\begin{array}{l}\text { Butt, Frederickson } \\
\text { and Morris (1992) }\end{array}$ & Fig. 4, p. 1325 \\
\hline$M_{m}$ & Maximum asymptotic mass & 8.5 & $g$ & Butt (1993) & Fig. 1, p. 136 \\
\hline$r_{B}$ & Growth constant & 0.0023 & /hour & Butt (1993) & Fig. 1, p. 136. \\
\hline$r_{m}$ & $\begin{array}{l}\text { Maximum rate of energy } \\
\text { allocation to reproduction }\end{array}$ & $2.10 \times 10^{-4}$ & $\mathrm{~kJ} / \mathrm{g} / \mathrm{hour}$ & $\begin{array}{l}\text { Butt, Frederickson } \\
\text { and Morris (1992) }\end{array}$ & Fig. 1, p. 1322. \\
\hline$T_{0}$ & Incubation period & 90 & days & $\begin{array}{l}\text { Butt, Frederickson } \\
\text { and Morris (1992) }\end{array}$ & Fig. 3, p. 1323 \\
\hline$T_{\text {ref }}$ & Reference temperature & 288.15 & kelvin & $\begin{array}{l}\text { Butt, Frederickson } \\
\text { and Morris (1992) }\end{array}$ & p. 1325 \\
\hline$\mu$ & Background mortality rate & 0.18 & $\% /$ day & (Daniel 1990) & $\begin{array}{l}\text { Table } 5 \text { (p. 31) and } \\
\text { Table } 6 \text { (p. 32) for } 10- \\
17.5^{\circ} \mathrm{C}\end{array}$ \\
\hline
\end{tabular}

This article is protected by copyright. All rights reserved. 
Table 2. Experimental conditions from published laboratory studies replicated by EEEworm to validate the models ability to predict $L$. terrestris life cycle processes with independent data. $N$ is number of individuals per experiment, SCS is separated cattle solids and $E_{x}$ is the energy content of food.

\begin{tabular}{|c|c|c|c|c|c|c|c|}
\hline Study & $\mathbf{N}$ & $\begin{array}{l}\text { Initial } \\
\text { mass }(g)\end{array}$ & Food source & $\begin{array}{l}\text { Food/soil } \\
\text { quantity } \\
\text { (g) }\end{array}$ & Ex (kJ/g) & $\begin{array}{l}\text { Temp } \\
\left({ }^{\circ} \mathrm{C}\right)\end{array}$ & $\begin{array}{l}\text { Soil } \\
\text { Moisture } \\
(\%)\end{array}$ \\
\hline $\begin{array}{l}\text { Lowe and Butt } \\
(2002)\end{array}$ & $(1)+2$ & (5) 0.055 & $\begin{array}{l}\text { Milled and } \\
\text { unmilled SCS }\end{array}$ & $60 / 900$ & $0.90-1.15$ & 15 & 25 \\
\hline $\begin{array}{l}\text { Berry and Jordan } \\
(2001)\end{array}$ & 1 & 0.07 & Horse manure & $10 / 750$ & 1.02 & $10-30$ & $20-30$ \\
\hline $\begin{array}{l}\text { Daniel, Kohli and } \\
\text { Bieri (1996) }\end{array}$ & 1 & 0.875 & None & $0 / 450$ & 0 & $10-25$ & 40 \\
\hline Butt (1993) & 4 & 3.3 & SCS & $500 / 1500$ & 2.05 & 20 & $25-30$ \\
\hline Butt (2011) & 1 & 6.53 & Horse manure & $100 / 600$ & 1.19 & 15 & 25 \\
\hline Butt (2011) & 1 & 7.32 & Birch leaves & $100 / 600$ & $1.19-1.20$ & 15 & 25 \\
\hline
\end{tabular}
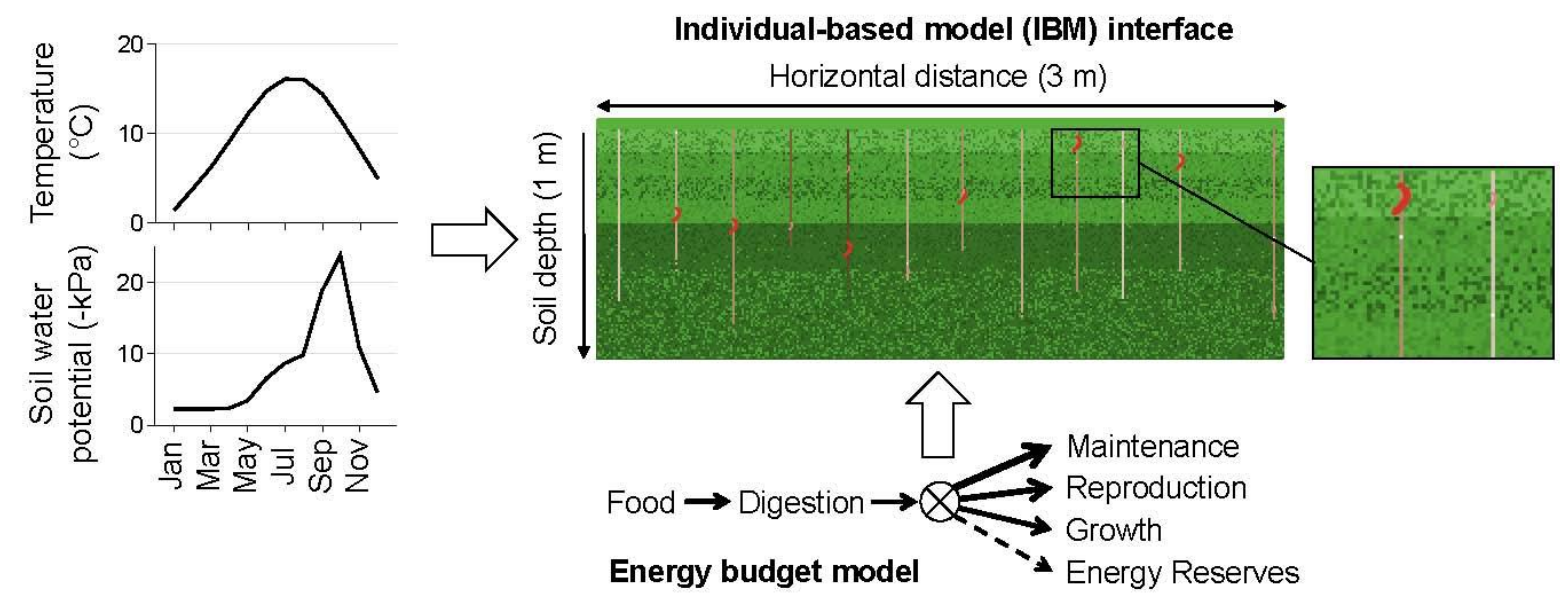

This article is protected by copyright. All rights reserved. 


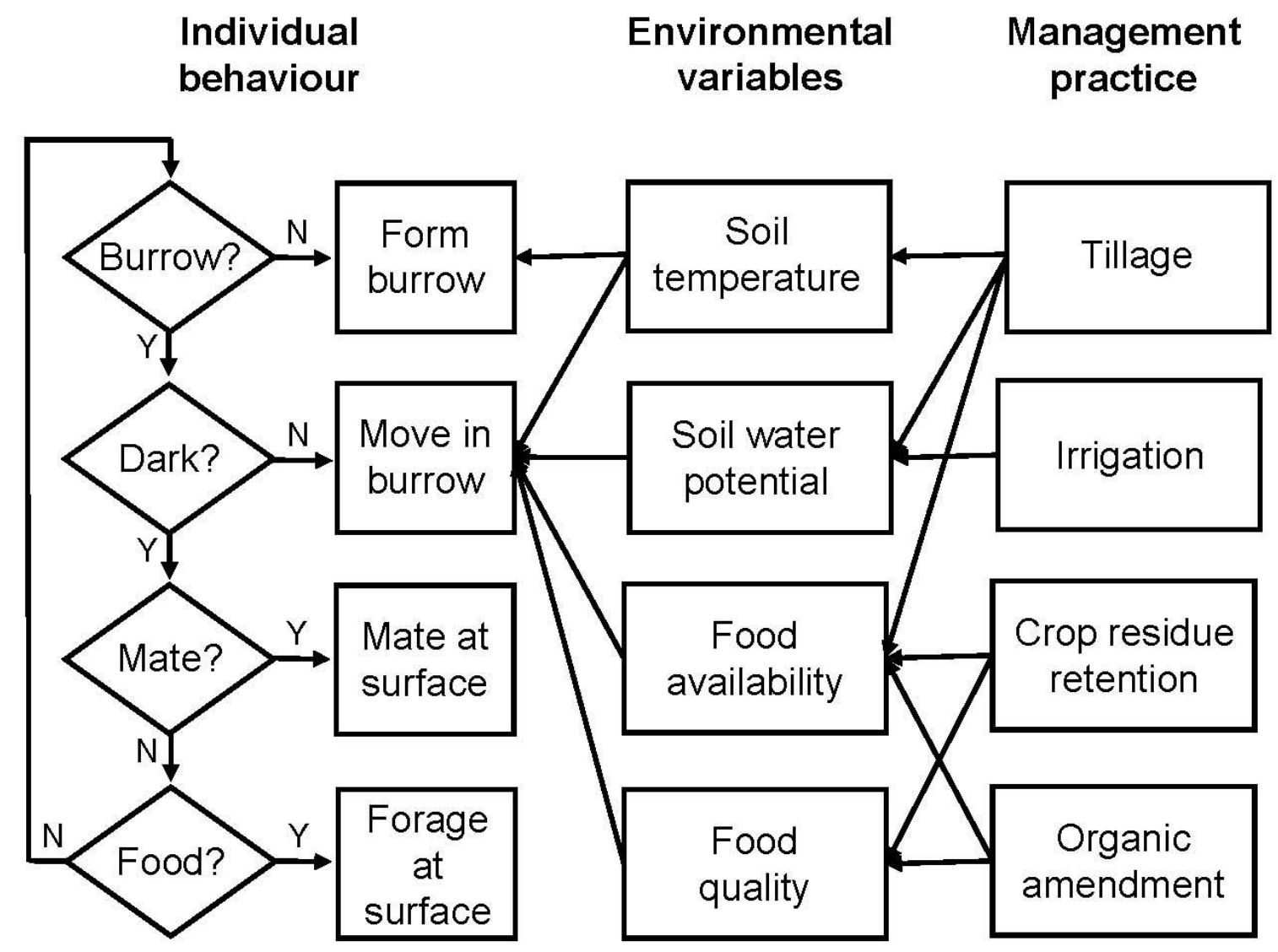

(a) Historical data

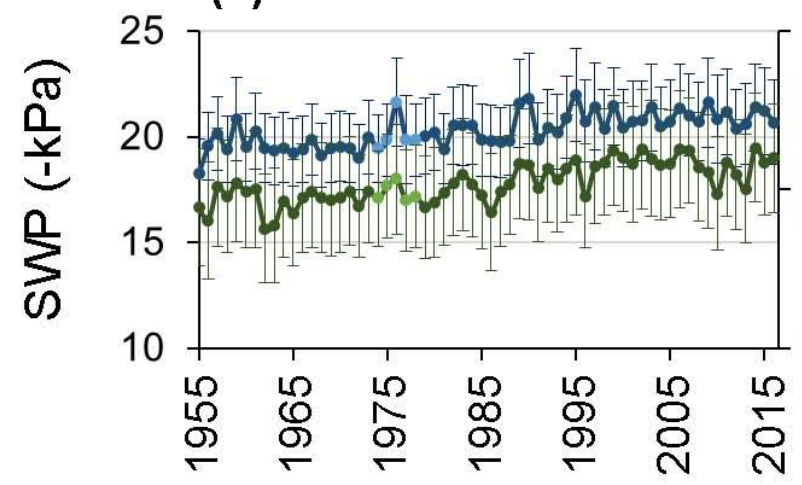

(b) Baseline projection

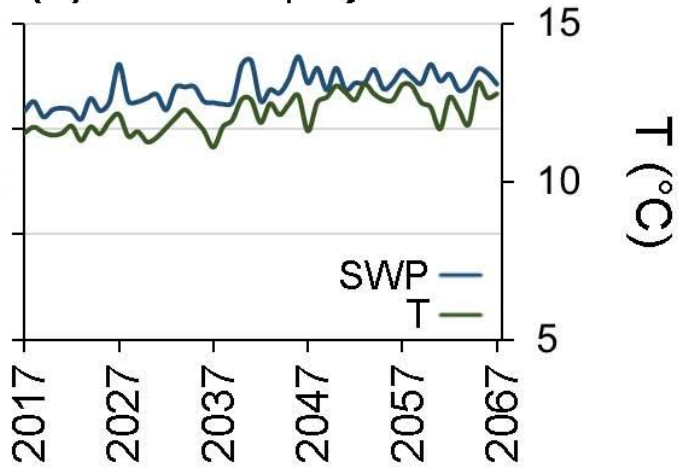



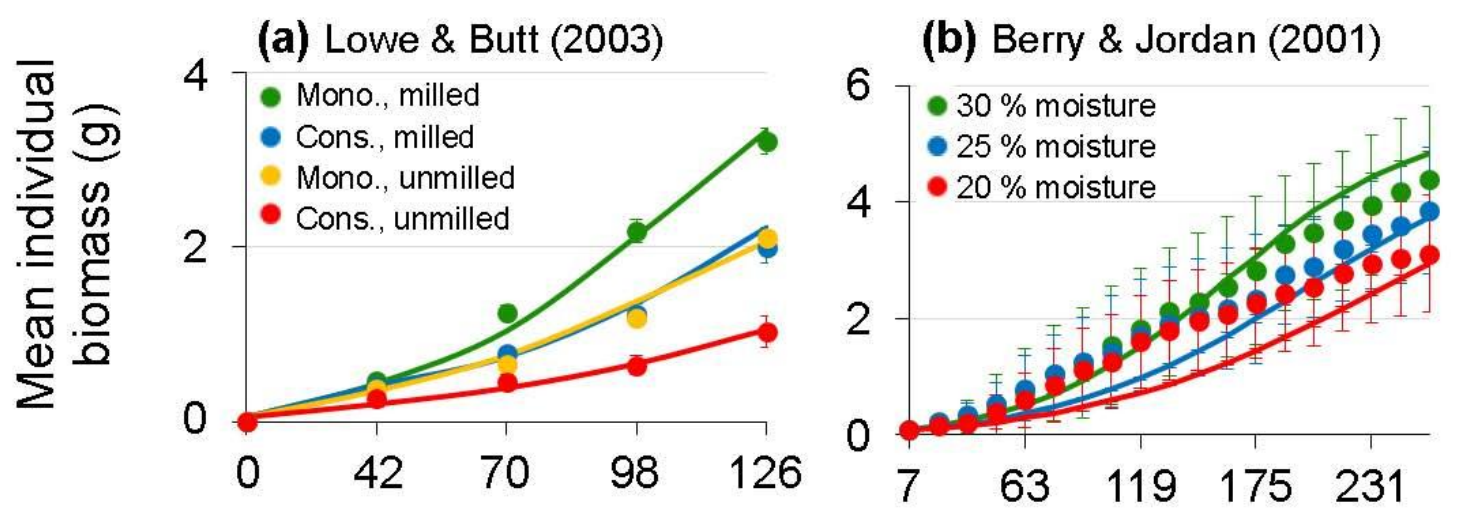

(c) Daniel et al. (1996)

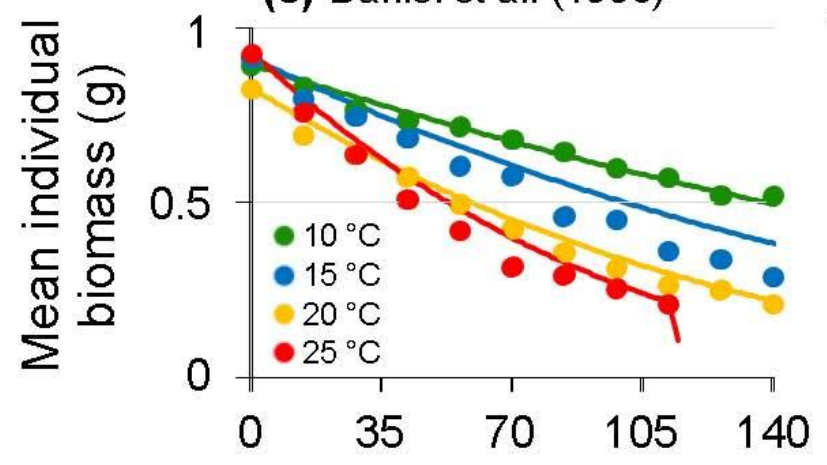

(d) Butt (2011)

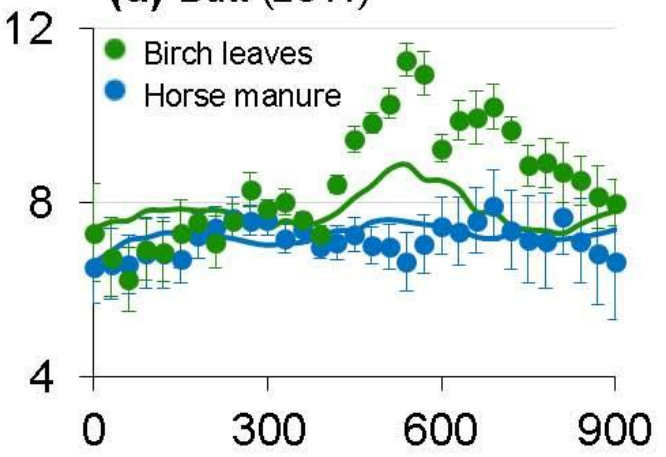

(e) Butt (1993)
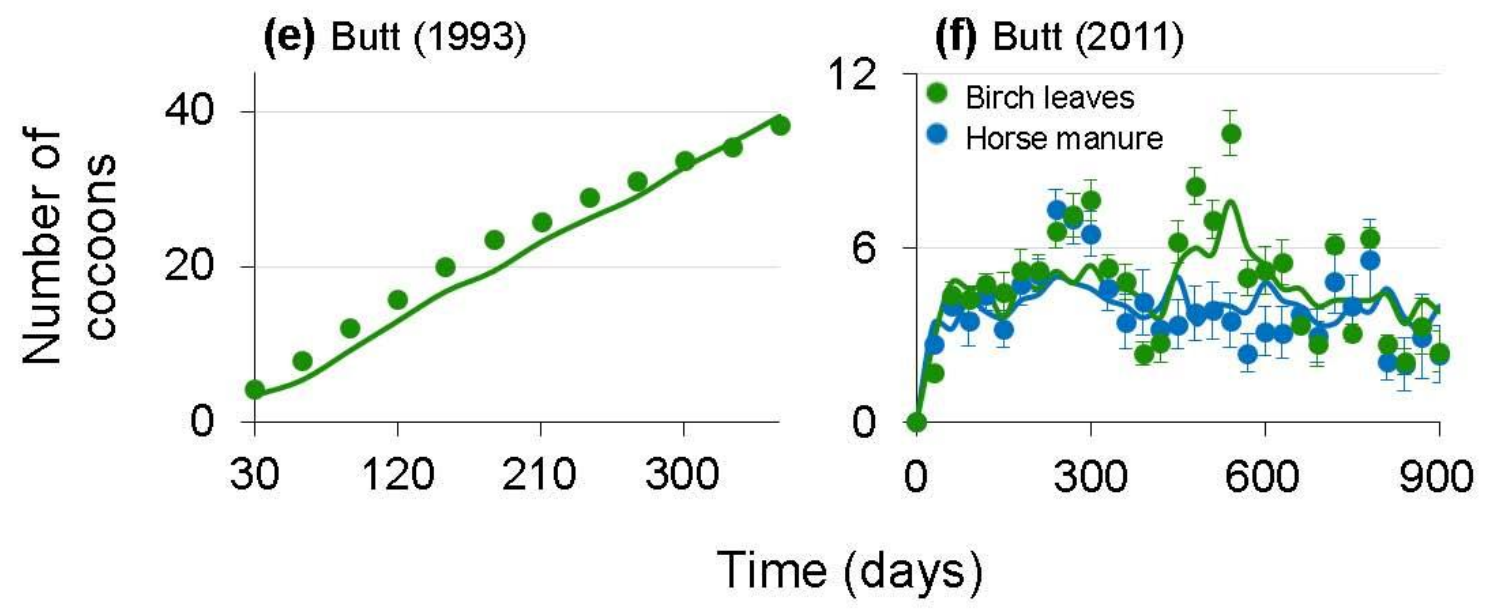

This article is protected by copyright. All rights reserved. 

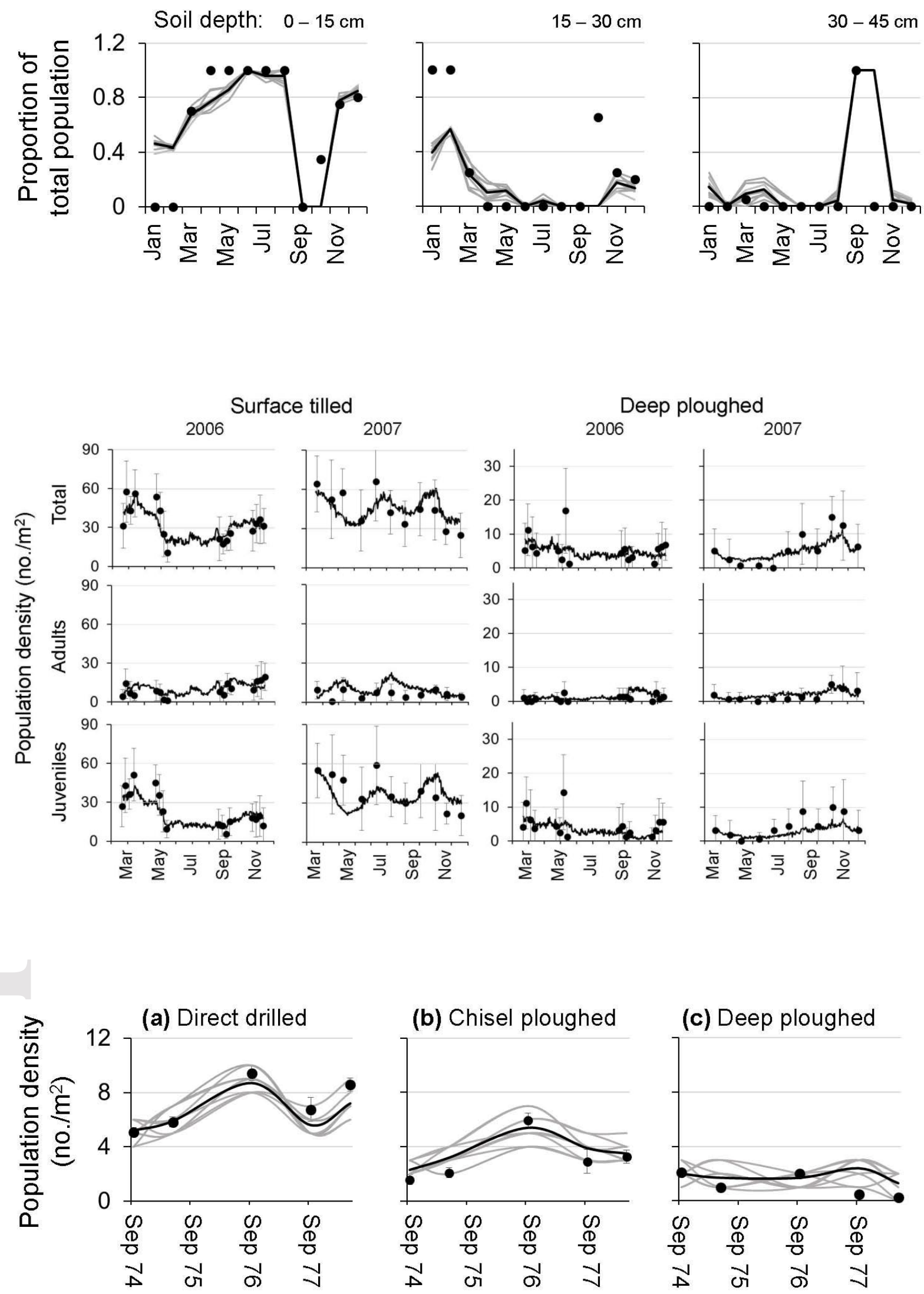

This article is protected by copyright. All rights reserved. 

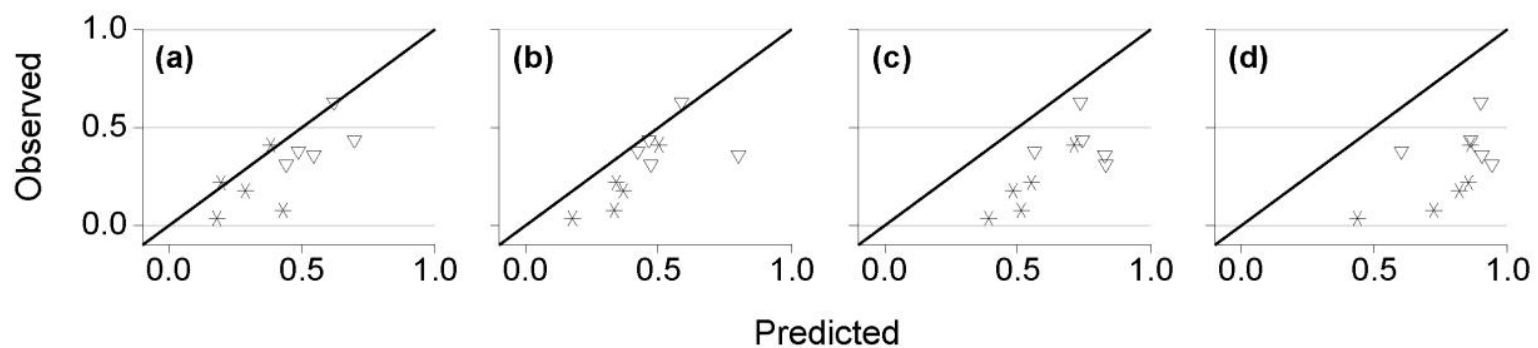

(a)

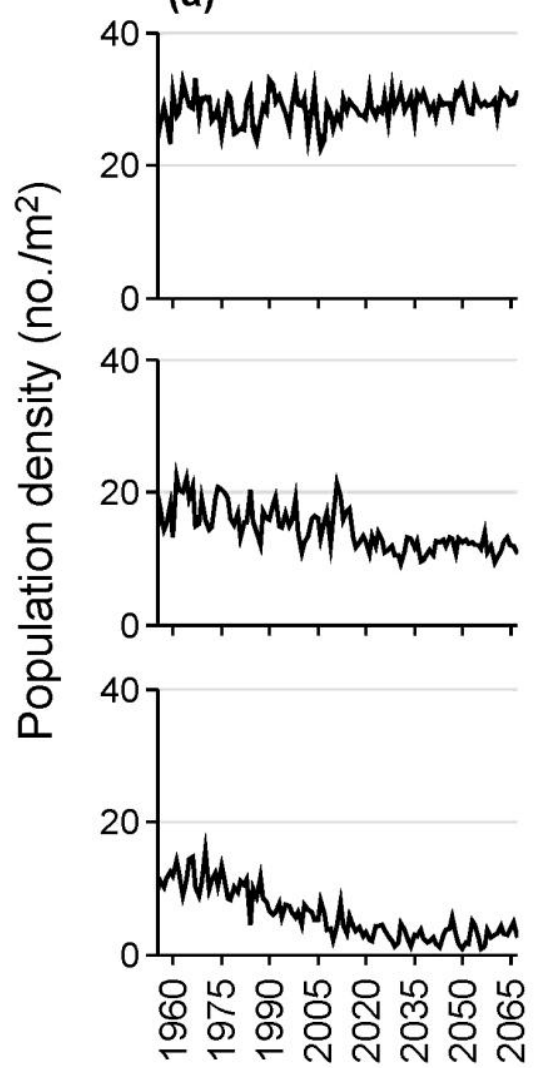

(b)

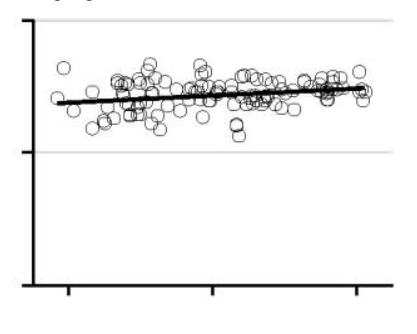

(c)
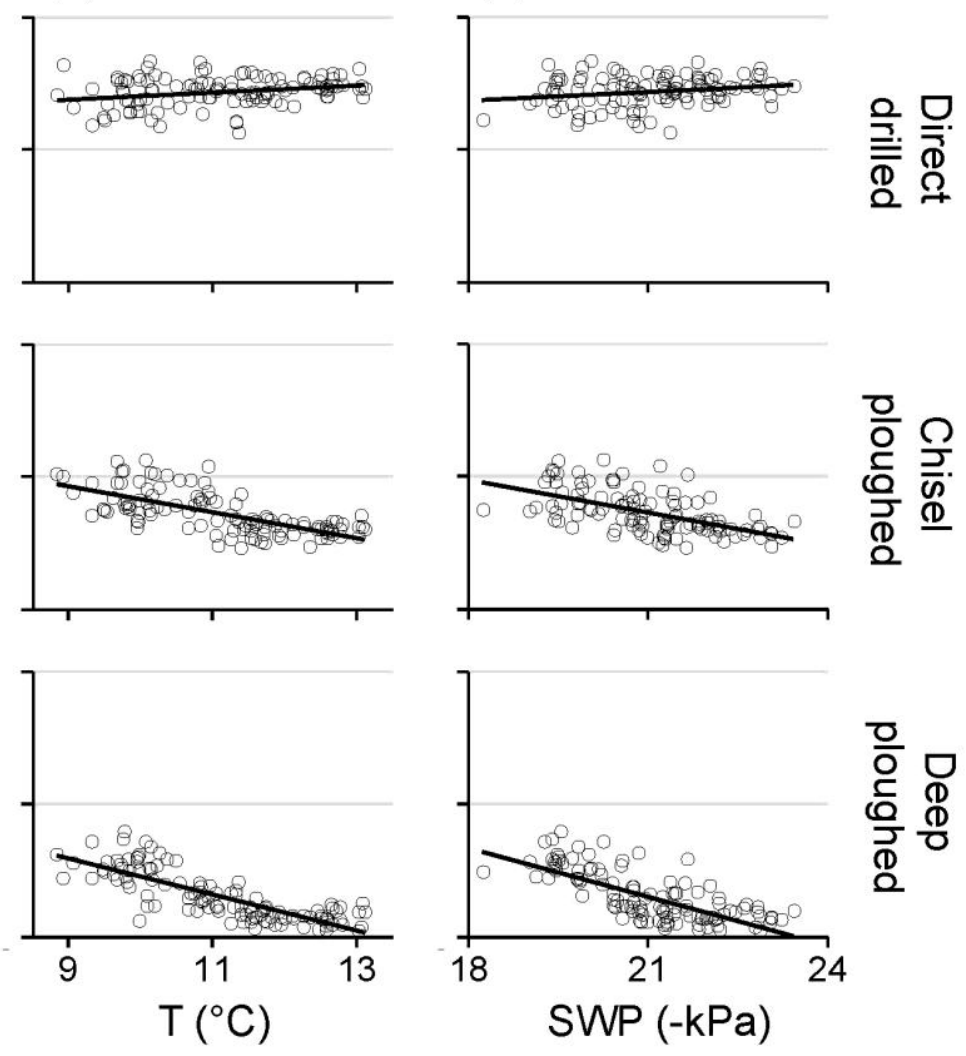

This article is protected by copyright. All rights reserved. 